\title{
Contribution of Endogenous Enkephalins to the Enhanced Analgesic Effects of Supraspinal $\mu$ Opioid Receptor Agonists after Inflammatory Injury
}

\author{
Robert W. Hurley and Donna L. Hammond \\ Department of Anesthesia and Critical Care and The Committee on Neurobiology, University of Chicago, Chicago, Illinois \\ 60637
}

This study examined a mechanism responsible for the enhanced antihyperalgesic and antinociceptive effects of the $\mu$ opioid receptor agonist (ORA) [D-Ala ${ }^{2}, \mathrm{NMePhe}^{4}$, Gly ${ }^{5}$ ol]enkephalin (DAMGO) microinjected in the rostroventromedial medulla (RVM) of rats with inflammatory injury induced by injection of complete Freund's adjuvant (CFA) in one hindpaw. In rats injected with CFA $4 \mathrm{hr}$ earlier, microinjection of the $\mu$ opioid receptor antagonist D-Phe-Cys-Tyr-D-Trp-Arg-Thr-PenThr- $\mathrm{NH}_{2}$ (CTAP) in the RVM antagonized both the marginal enhancement of the potency of DAMGO and its antinociceptive effect. The $\delta$ opioid receptor antagonist naltriben (NTB) was without effect. In rats injected with CFA 2 weeks earlier, CTAP antagonized the effects of DAMGO to a lesser extent. However, NTB completely prevented the enhancement of the potency of DAMGO, whereas it did not antagonize DAMGO's antinociceptive effects. Microinjection of NTB alone, but not CTAP in the RVM of CFA-treated rats, enhanced the hyperalgesia present in the ipsilateral hindpaw and induced hyperalgesia in the contralateral, uninjured hindpaw. These results suggest that persistent inflammatory injury increased the release in the RVM of opioid peptides with preferential affinity for the $\delta$ opioid receptor, which can interact in a synergistic or additive manner with an exogenously administered $\mu$ opioid receptor agonist. Indeed, the levels of $\left[\mathrm{Met}^{5}\right]$ enkephalin and [ Leu $\left.^{5}\right]$ enkephalin were increased in the RVM and in other brainstem nuclei in CFAtreated rats. This increase most likely presents a compensatory neuronal response of the CNS of the injured animal to mitigate the full expression of inflammatory pain and to enhance the antinociceptive and antihyperalgesic effects of exogenously administered $\mu$ opioid receptor analgesics.

Key words: $\mu$ opioid receptor; $\delta$ opioid receptor; antinociception; complete Freund's adjuvant; hyperalgesia; nucleus raphe magnus
Peripheral inflammatory injury alters the pharmacology and physiology of primary afferent fibers that convey tactile and nociceptive information (Noguchi et al., 1988; Schaible and Schmidt, 1988; Donaldson et al., 1992; Ji et al., 1995; Leslie et al., 1995; Neumann et al., 1996; Tanaka et al., 1998), as well as the pharmacology and physiology of the dorsal horn neurons on which they synapse (Hylden et al., 1989; Noguchi et al., 1989; Weihe et al., 1989; Noguchi and Ruda, 1992; McCarson and Krause, 1994; Goff et al., 1998). More recently, peripheral inflammation has been recognized to also affect the efferent pain modulatory pathways. For example, persistent inflammatory injury can enhance either the inhibition or facilitation of spinal nociceptive transmission by medullary or pontine neurons (Schaible et al., 1991; Herrero and Cervero, 1996; Ren and Dubner, 1996; Tsuruoka and Willis, 1996; Urban et al., 1996, 1999; Kauppila et al., 1998; Wei et al., 1998, 1999; MacArthur et al., 1999; Terayama et al., 2000). Alterations in the activity of supraspinal neurons were inferred in most of these studies from lesion-induced changes in response latency or in the responses of the dorsal horn neurons to which these neurons project. However, insights into the response of supraspinal neurons to persistent inflammatory

Received Nov. 13, 2000; revised Jan. 16, 2001; accepted Jan. 19, 2001.

This work was supported by United States Public Health Service Grants DA06736 to D.L.H. and DA05784 to R.W.H.

Correspondence should be addressed to Dr. Donna L. Hammond, Department of Anesthesia 6505-2 JCP, University of Iowa, 200 Hawkins Drive, Iowa City, IA 52242. E-mail: donna-hammond@uiowa.edu.

Copyright (C) 2001 Society for Neuroscience 0270-6474/01/212536-10\$15.00/0 nociception can also be gained from changes in the potency or efficacy of drugs administered directly into these sites. We recently reported that the potency of a $\mu$ or $\delta$ opioid receptor agonist (ORA) microinjected in the rostroventromedial medulla (RVM) is enhanced in a time-dependent manner after the injection of complete Freund's adjuvant (CFA) in one hindpaw (Hurley and Hammond, 2000). This enhancement is evident as an increase in the antihyperalgesic potency of these agonists as determined by their ability to alleviate hyperalgesia on the ipsilateral, inflamed hindpaw, and also as an increase in antinociceptive potency as determined by their ability to suppress nociceptive responses of the contralateral, uninjured hindpaw. Although numerous mechanisms may be considered, there is substantial evidence that $\mu$ and $\delta$ ORAs can interact in an additive or synergistic manner to produce antinociception (Roerig and Fujimoto, 1989; Porreca et al., 1990, 1992; Malmberg and Yaksh, 1992; Adams et al., 1993; Rossi et al., 1994; He and Lee, 1998). This study therefore investigated whether the enhanced antinociceptive and antihyperalgesic potency of $\left[\mathrm{D}-\mathrm{Ala}^{2}-\mathrm{NMePhe}^{4}-\mathrm{Gly}^{5}\right.$ ol]enkephalin (DAMGO) results from the interaction of this exogenously administered $\mu$ ORA with endogenous enkephalins, which preferentially act at $\delta$ opioid receptors and the synthesis of which is increased in brainstem nuclei as a consequence of persistent nociception. Specifically, initial experiments characterized the ability of $\mu$ and $\delta$ opioid receptor selective antagonists to attenuate the enhanced antihyperalgesic and antinociceptive effects of DAMGO microinjected in the RVM of rats that had received an injection of CFA in one hindpaw either $4 \mathrm{hr}$ or 2 
weeks earlier. Subsequent experiments examined whether microinjection of these antagonists by themselves enhanced CFAinduced thermal hyperalgesia. Finally, this study measured the levels of $\left[\mathrm{Met}^{5}\right]$ enkephalin and $\left[\mathrm{Leu}^{5}\right]$ enkephalin in brainstem nuclei at various times after the injection of CFA.

\section{MATERIALS AND METHODS}

Animals. Male Sprague-Dawley rats (Sasco, Kingston, NY) weighing 275-350 gm were prepared with an intracerebral guide cannula aimed at the RVM and allowed to recover for 6-7 d as described previously (Hurley et al., 1999). Baseline measurements of paw withdrawal latency (PWL) to noxious radiant heat were then made for each hindpaw (Hargreaves et al., 1988; Dirig et al., 1997), after which $150 \mu \mathrm{l}$ of either CFA [100 $\mu \mathrm{g}$ Mycobacterium butyricum, 85\% Marcol 52, and 15\% Aracel A mannide monoemulsifier (Calbiochem, LaJolla, CA)] or saline $(0.9 \%)$ was injected into the plantar surface of one hindpaw under brief halothane anesthesia. The rats were then returned to their home cage for a period of either $4 \mathrm{hr}$ or 2 weeks. These time points were chosen to represent the acute and chronic phases of inflammatory injury. Longer periods of inflammation were not examined to avoid the possible systemic spread of CFA and induction of a polyarthritic state. Animals were tested only once.

Experimental design. The first series of experiments verified the specificity of the agonists and antagonists at the doses injected in this study and confirmed that the antinociceptive effect of DAMGO microinjected in the RVM of saline-treated rats was mediated by a $\mu$ opioid receptor. For these experiments, baseline PWL was redetermined $4 \mathrm{hr}$ or 2 weeks after the intraplantar injection of saline. DAMGO was then coadministered with $0.33 \mu \mathrm{g}$ of the $\mu$ opioid receptor antagonist D-Phe-Cys-TyrD-Trp-Arg-Thr-Pen-Thr- $\mathrm{NH}_{2}$ (CTAP), and PWL was redetermined 15, 30 , and $60 \mathrm{~min}$ later. In other experiments, either saline or $80 \mathrm{ng}$ of naltriben $(\mathrm{NTB})$, a $\delta_{2}$ opioid receptor antagonist, was microinjected in the RVM 15 min before microinjection of DAMGO at the same site. Paw withdrawal latency was redetermined 15, 30, and 60 min later. This study was restricted to rats that received an intraplantar injection of saline $4 \mathrm{hr}$ earlier. Other experiments confirmed the specificity of the antagonists and were largely restricted to rats that had received an intraplantar injection of saline $4 \mathrm{hr}$ earlier to minimize animal usage. After redetermination of baseline PWL, $0.33 \mu \mathrm{g}$ of CTAP was coadministered with the $\delta_{2}$ ORA [D-Ala ${ }^{2}, \mathrm{Glu}^{4}$ ] enkephalin (DELT). In other rats, 8 or $80 \mathrm{ng}$ of NTB was administered in the RVM 5 min before microinjection of DELT at the same site. Paw withdrawal latency in both experiments was redetermined 15, 30, and $60 \mathrm{~min}$ after the injection of DELT. The order in which the antagonists and agonists were administered in all studies ensured that their peak effects would coincide.

The second series of experiments examined the extent to which $\mu$ or $\delta$ opioid receptors mediate the enhanced antihyperalgesic and antinociceptive effects of DAMGO microinjected in the RVM of CFA-treated rats. These experiments were conducted in rats that had received an intraplantar injection of CFA either $4 \mathrm{hr}$ or 2 weeks earlier, because these times corresponded to the times at which the potency of DAMGO was minimally and maximally enhanced, respectively (Hurley and Hammond, 2000). In these experiments, baseline PWL was redetermined $4 \mathrm{hr}$ or 2 weeks after the injection of CFA. DAMGO was then coadministered in the RVM with $0.33 \mu \mathrm{g}$ of CTAP or was administered in the RVM $15 \mathrm{~min}$ after microinjection of either 8 or $80 \mathrm{ng}$ of NTB. Paw withdrawal latency was redetermined 15, 30, and 60 min later. Doses of DAMGO in excess of $100 \mathrm{ng}$ were not tested because of the occurrence of profound catatonia and other behaviors that interfered with the measurement of PWL.

The third series of experiments examined whether microinjection of the opioid receptor antagonists alone altered PWL. In these studies, either saline, 8 or $80 \mathrm{ng}$ of NTB, or $0.33 \mu \mathrm{g}$ of CTAP was microinjected into the RVM of rats that had received an intraplantar injection of either saline or CFA $4 \mathrm{hr}$ or 2 weeks earlier. To ensure that antagonist-induced alterations in body temperature did not confound the measurements of thermal nociceptive threshold (Berge et al., 1988), paw temperature and paw diameter were also measured as described previously (Hurley and Hammond, 2000). The assessment of antagonist effects on paw temperature and diameter was restricted to rats that had received an injection of CFA $4 \mathrm{hr}$ earlier to minimize the number of rats used. At the conclusion of testing, the rats were killed by $\mathrm{CO}_{2}$ inhalation, and the brains were removed for histological localization of the microinjection sites (Hurley and Hammond, 2000).
The final series of experiments examined whether induction of inflammatory nociception altered the levels of $\left[\mathrm{Met}^{5}\right]$ enkephalin or $\left[\mathrm{Leu}^{5}\right]$ enkephalin in the brainstem. After intraplantar injection of $150 \mu \mathrm{l}$ of either CFA or saline into the plantar surface of one hindpaw, the rats were returned to their home cage for a period of either $4 \mathrm{hrs}, 4 \mathrm{~d}$, or 2 weeks. These time points were chosen to represent the acute, subacute, and chronic phases of inflammatory injury. To obtain tissue, the rats were deeply anesthetized with ketamine $(85 \mathrm{mg} / \mathrm{kg}$, i.p. $)$ and xylazine $(9$ $\mathrm{mg} / \mathrm{kg}$, i.p.), supplemented by sodium pentobarbital, and then exsanguinated. The midbrain, pons, and medulla were cut into transverse blocks 2-3 mm in depth and rapidly frozen for removal of the nuclei of interest using a standardized array of tissue micropunches (Stoelting, Chicago, IL). These regions included the nucleus raphe magnus (NRM), ipsilateral and contralateral nucleus reticularis gigantocellularis pars $\alpha$ $(\mathrm{NGCp} \alpha)$, ventrolateral periaqueductal gray (PAG) at the levels of the pons, and the midbrain, ipsilateral, and contralateral parabrachial nuclei, and ipsilateral and contralateral microcellular tegmentum.

Radioimmunoassay. Tissue samples were homogenized in $1 \mathrm{~N}$ acetic acid and centrifuged at $10,000 \times g$ for $20 \mathrm{~min}$ at $4^{\circ} \mathrm{C}$, and the pellet was extracted again in $1 \mathrm{~N}$ acetic acid and centrifuged. Supernatants were combined, lyophilized, and stored at $-80^{\circ} \mathrm{C}$ until analysis. Protein was determined by the bicinchoninic acid method (Smith et al., 1985). Levels of $\left[\mathrm{Leu}^{5}\right]$ enkephalin and $\left[\mathrm{Met}^{5}\right]$ enkephalin in each sample were determined by radioimmunoassay according to the manufacturer's protocol (Peninsula Laboratories, San Carlos, CA). Tissue samples from three to four CFA-treated rats at each time point were processed concurrently with tissue samples from two to three saline-treated rats. Levels were expressed as picomole per milligram of protein. Because the recovery of a known amount of $\left[\mathrm{Met}^{5}\right]$ enkephalin added at the outset of the experiment ranged from 95 to $100 \%$, values were not corrected for any potential loss of analyte during the assay procedure.

Statistical analyses: behavioral experiments. Two-way ANOVAs for repeated measures were used to compare the effect of DAMGO in the presence of antagonist with that in the absence of antagonist, or to compare the effects of the antagonists alone on response latency, paw temperature, or paw diameter with those of saline. The Newman-Keuls test was used for post hoc comparisons among the individual group means. Dose-response relationships for DAMGO were determined by linear regression analysis using the individual PWLs measured at the time of peak effect, which was determined previously to be $15 \mathrm{~min}$ (Hurley and Hammond, 2000). Fieller's theorem as applied by Finney (1964) was used to determine the $95 \%$ confidence limits. Analysis of covariance was used to compare $\mathrm{ED}_{50}$ values for DAMGO in the presence and absence of the antagonists. Calculation of the $\mathrm{ED}_{50}$ values for the antihyperalgesic and antinociceptive effects of DAMGO were based on the entire dose-effect relationship. The $\mathrm{ED}_{50}$ value was defined as the dose of agonist that produced $50 \%$ of the maximum possible increase in PWL. In the noninflamed hindpaw, the average baseline PWL was $\sim 10$ $\mathrm{sec}$, and the maximum response latency was $20 \mathrm{sec}$. Therefore, the criterion latency for calculation of the $\mathrm{ED}_{50}$ value for production of antinociception on the noninflamed hindpaw was set to $15 \mathrm{sec}$. In the inflamed hindpaw, the mean baseline PWL was $3.6 \pm 0.1(n=154)$ and $5.7 \pm 0.1 \mathrm{sec}(n=190)$ at $4 \mathrm{hr}$ and 2 weeks after injection of CFA, respectively. To examine the antihyperalgesic (as opposed to the antinociceptive) potency of the agonists, the maximum response latency was set to $10 \mathrm{sec}$, i.e., a return of PWL to normal threshold. The criterion latency for calculation of the $\mathrm{ED}_{50}$ for the production of antihyperalgesia on the inflamed hindpaw $4 \mathrm{hr}$ or 2 weeks after injection of CFA was therefore set to 6.8 and $7.9 \mathrm{sec}$, respectively.

Statistical analyses: radioimmunoassay. Values for individual samples that were greater than or less than 1.5 times the interquartile range for the group plus the third quartile or minus the first quartile, respectively, were excluded from analysis. With one exception, no significant differences were observed in the levels of either peptide in any region as a function of time after injection of saline. The data for these three time points were pooled for each region of interest to yield a single salinetreated control group for comparisons with CFA-treated rats. One-way ANOVAs followed by a post hoc Bonferroni $t$ test were used to compare levels of the peptides in the three CFA-treatment groups with that in the saline-treatment group. Where assumptions of normality and equal variance were not met, a Kruskal-Wallis one-way ANOVA on ranks and Dunn's test were used for these comparisons.

Drugs. DAMGO [lot no. 121H58153; molecular weight $(\mathrm{MW})=513.6$ ] and DELT (lot no. 88H13351; MW = 782.5) were purchased from Sigma (St. Louis, MO). CTAP (lot no. MPSP-13-02; MW = 1103) and NTB 

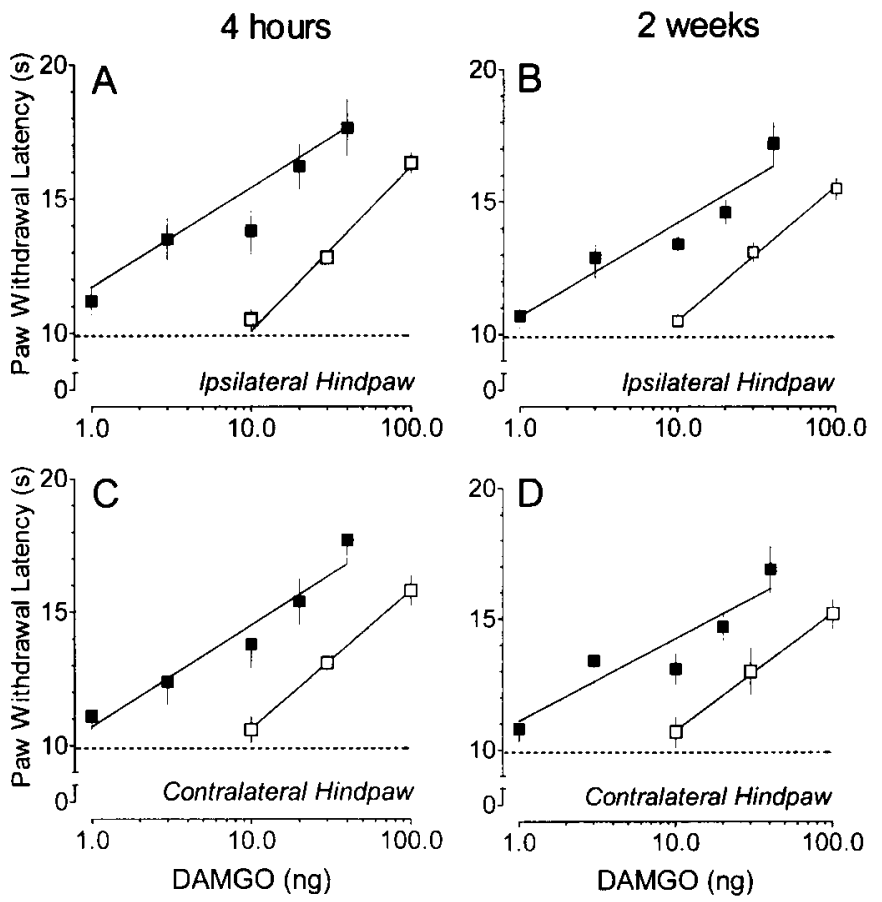

Figure 1. Dose-response relationships for DAMGO alone ( $\square$ ) and in combination with $0.33 \mu \mathrm{g}$ of CTAP $(\square)$ in rats that received an intraplantar injection of saline either $4 \mathrm{hr}(A, C))$ or 2 weeks $(B, D)$ earlier. $A, B$, Rightward shift for the ipsilateral hindpaw. $C, D$, Rightward shift for the contralateral hindpaw. Solid lines represent the least square linear regression of the individual data at $15 \mathrm{~min}$, the time of peak effect. Each symbol is the mean \pm SEM of determinations in 6-11 rats. The dashed horizontal line in each panel represents the average baseline PWL of rats after the intraplantar injection of saline and before the microinjection of any drug. Data for DAMGO alone are taken from Hurley and Hammond (2000).

(lot no. PG-111-83; MW = 511.6) were obtained from the Research Technology Branch of the National Institute of Drug Abuse (Bethesda, MD). All drugs were dissolved in saline, $\mathrm{pH} 7.4$, and delivered in a 0.25 $\mu$ l volume via a 33 gauge stainless steel injector that extended $3 \mathrm{~mm}$ beyond the tip of the guide cannula.

\section{RESULTS}

\section{Distribution of microinjection sites}

Microinjection sites in this study were predominantly distributed throughout the rostrocaudal extent of the NRM, with a smaller percentage of sites within the adjacent NGCp $\alpha$. The distribution of sites in the NRM and NGCp $\alpha$ did not differ systematically among the various treatment groups and was comparable to that depicted in previous studies from this laboratory (Thomas et al., 1995; Hurley et al., 1999, 2000) and is therefore not illustrated here. Very few microinjection sites were located outside the NRM or NGCp $\alpha$. Microinjection of DAMGO alone (Hurley and Hammond, 2000) or in combination with the antagonists (data not shown) was ineffective at these sites. In view of the limited number of sites and the lack of efficacy of the agonist, these sites were excluded from further analysis.

\section{The antinociceptive effect of DAMGO is mediated by a $\mu$ opioid receptor in saline-treated rats}

Coadministration of $0.33 \mu \mathrm{g}$ of CTAP with DAMGO produced a parallel, rightward shift in the dose-response relationships of DAMGO for both the ipsilateral and contralateral hindpaw of saline-treated rats (Fig. 1). The magnitude of the shift averaged five-fold and was consistent among rats that had received an intraplantar injection of saline $4 \mathrm{hr}$ or 2 weeks earlier (Table 1). In contrast, this dose of CTAP did not antagonize the increase in PWL produced by microinjection of the $\delta_{2}$ ORA DELT in the RVM of rats that received an intraplantar injection of saline $4 \mathrm{hr}$ earlier (Fig. 2). Furthermore, the increase in PWL produced by either 3 or $20 \mathrm{ng}$ of DAMGO was not antagonized by previous microinjection of $80 \mathrm{ng}$ of NTB, a $\delta_{2}$ opioid receptor antagonist, in the RVM. This dose of NTB completely antagonized an equiantinociceptive dose of DELT (Fig. 2). Similar specificity of the antagonists was demonstrated in rats that had received an intraplantar injection of saline 2 weeks earlier (data not shown).

\section{$\mu$ and $\delta$ opioid receptors mediate the enhanced antihyperalgesic effects of DAMGO in the CFA-treated rat in a time-dependent manner: findings for the ipsilateral hindpaw}

In rats injected $4 \mathrm{hr}$ earlier with CFA, coadministration of CTAP with DAMGO shifted the dose-response relationship for the antihyperalgesic effect of DAMGO to the right by 10 -fold with a slight decrease in slope (Fig. $3 A$, Table 1 ). In contrast, in rats that had received an injection of CFA 2 weeks earlier, coadministration of CTAP with DAMGO shifted the dose-response relationship for DAMGO for the ipsilateral hindpaw to the right in a parallel manner, but only by 3.5 -fold (Fig. $3 B$, Table 1 ).

To examine the role of the $\delta_{2}$ opioid receptor, it was necessary to reduce the dose of NTB from 80 to $8 \mathrm{ng}$ (see below). In rats that had received an intraplantar injection of CFA $4 \mathrm{hr}$ earlier, 8 ng NTB did not significantly shift the dose-response relationship of DAMGO to the right (Fig. $3 A$, Table 1). However, in rats that had received an intraplantar injection of CFA 2 weeks earlier, this dose of NTB shifted the dose-response relationship of DAMGO to the right by 12.5 -fold in a competitive manner (Fig. $3 B$, Table 1 ).

\section{$\mu$ and $\delta$ opioid receptors mediate the enhanced antinociceptive effects of DAMGO in the CFA-treated rat in a time-dependent manner: findings for the contralateral hindpaw}

In rats that had received an injection of CFA $4 \mathrm{hr}$ earlier, coadministration of CTAP with DAMGO shifted the doseresponse relationship for the antinociceptive effect of DAMGO in the contralateral hindpaw to the right by 17 -fold (Fig. $3 C$, Table 1). This large shift was anticipated on the basis that CTAP should not only antagonize the antinociceptive effects of DAMGO to the same extent as in saline-treated rats, but should also antagonize the enhancement of the antinociceptive effect of DAMGO if this latter effect involved $\mu$ opioid receptors. Indeed, the 17.1-fold shift produced by CTAP in CFA-treated rats at $4 \mathrm{hr}$ closely approximated the product of the antagonism of the enhancement (2.4-fold rightward shift) and antagonism of the antinociceptive effects of DAMGO (5.2-fold rightward shift). Furthermore, the $\mathrm{ED}_{50}$ of DAMGO in the presence of CTAP in CFA-treated rats $(94.1 \mathrm{ng})$ did not differ from that in saline-treated rats $(70.1 \mathrm{ng}$; $p>0.1)$.

In rats that had received an injection of CFA 2 weeks earlier, coadministration of CTAP with DAMGO shifted the doseresponse relationship for DAMGO for the contralateral hindpaw to the right by 20 -fold. This rightward shift included the "dog-leg" portion of the DAMGO dose-response relationship wherein the 
Table 1. ED $_{50}$ values in nanograms (and 95\% confidence limits) for DAMGO administered alone and in combination with antagonists in the RVM of rats that received an intraplantar injection of saline or CFA

\begin{tabular}{|c|c|c|c|c|c|c|c|c|}
\hline \multirow{2}{*}{$\begin{array}{l}\text { Intraplantar treat- } \\
\text { ment interval }\end{array}$} & \multicolumn{4}{|c|}{ Intraplantar saline } & \multicolumn{4}{|c|}{ Intraplantar CFA } \\
\hline & Ipsilateral & Dose ratio & Contralateral & Dose ratio & Ipsilateral & Dose ratio & Contralateral & Dose ratio \\
\hline \multicolumn{9}{|l|}{ Four hours } \\
\hline DAMGO & $\begin{array}{l}10.8 \\
(6.7-20.0)\end{array}$ & & $\begin{array}{l}13.4 \\
(8.1-28.1)\end{array}$ & & $\begin{array}{l}0.75 \\
(0.4-1.1)\end{array}$ & & $\begin{array}{l}5.5 \\
(3.3-8.5)\end{array}$ & \\
\hline DAMGO/CTAP & $\begin{array}{l}62.8^{* *} \\
(52.1-79.1)\end{array}$ & 5.8 & $\begin{array}{l}70.1^{* *} \\
(52.0-108.6)\end{array}$ & 5.2 & $\begin{array}{l}7.8^{* *} \\
(2.9-18.9)\end{array}$ & 10.4 & $\begin{array}{l}94.1^{* *} \\
(29.4-\text {-n.d. })\end{array}$ & 17.1 \\
\hline DAMGO/NTB & n.a. & & n.a. & & $\begin{array}{l}1.5 \\
(0.3-3.5)\end{array}$ & 2.0 & $\begin{array}{l}7.1 \\
(4.0-12.0)\end{array}$ & 1.3 \\
\hline \multicolumn{9}{|l|}{ Two weeks } \\
\hline DAMGO & $\begin{array}{l}16.7 \\
(10.4-34.0)\end{array}$ & & $\begin{array}{l}17.8 \\
(9.9-48.4)\end{array}$ & & $\begin{array}{l}0.02 \\
(0.009-0.04)\end{array}$ & & $\begin{array}{l}1.9 \\
(1.1-3.1)\end{array}$ & \\
\hline DAMGO/CTAP & $\begin{array}{l}75.9^{* *} \\
(55.6-120.8)\end{array}$ & 4.5 & $\begin{array}{l}89.0^{* *} \\
(54.2-247.7)\end{array}$ & 5.0 & $\begin{array}{l}0.07^{* *} \\
(0.02-0.2)\end{array}$ & 3.5 & $\begin{array}{l}38.9 \\
(23.1-66.4)\end{array}$ & 20.5 \\
\hline DAMGO/NTB & n.d. & & n.d. & & $\begin{array}{l}0.25^{* *} \\
(0.09-0.6)\end{array}$ & 12.5 & $\begin{array}{l}19.4^{* *} \\
(10.0-45.1)\end{array}$ & 10.2 \\
\hline
\end{tabular}

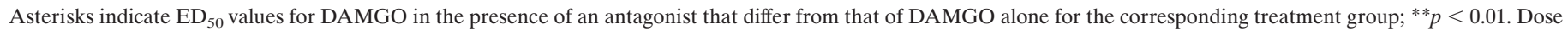


no antagonism and indicates that NTB did not antagonize the antinociceptive effects of DAMGO in saline-treated rats as illustrated in Figure 2.

effects of very low doses were enhanced. However, this shift was less than the 47-fold that was predicted by the product of the antagonism by CTAP of the enhancement of antinociceptive effects of DAMGO (9.4-fold rightward shift) and its antagonism of the antinociceptive effects of DAMGO (5.0-fold rightward shift). Indeed, the $\mathrm{ED}_{50}$ of DAMGO in the presence of CTAP in

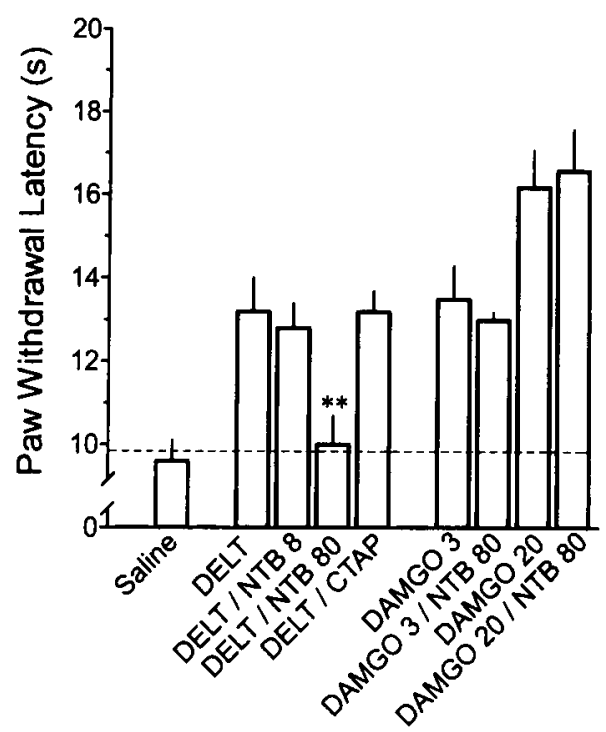

Figure 2. Specificity of the opioid receptor agonists and antagonists microinjected in the RVM is illustrated for rats that received an intraplantar injection of saline $4 \mathrm{hr}$ earlier. From the left to right, the bars depict the effects of saline, $1.25 \mu \mathrm{g}$ of DELT alone, $1.25 \mu \mathrm{g}$ of DELT with $8 \mathrm{ng}$ of NTB, $1.25 \mu \mathrm{g}$ of DELT with $80 \mathrm{ng}$ of NTB, $1.25 \mu \mathrm{g}$ of DELT with $0.33 \mu \mathrm{g}$ of CTAP, $3 \mathrm{ng}$ of DAMGO alone, $3 \mathrm{ng}$ of DAMGO with $80 \mathrm{ng}$ of NTB, $20 \mathrm{ng}$ of DAMGO alone, and $20 \mathrm{ng}$ of DAMGO with $80 \mathrm{ng}$ of NTB. Paw withdrawal values are expressed as the mean \pm SEM of determinations in six to eight rats. The PWL shown is that of the ipsilateral hindpaw 15 or 30 min after the microinjection of DAMGO or DELT in the RVM, which corresponds to their respective times of peak effect. The dashed horizontal line represents the average PWL determined after the intraplantar injection of saline and before the microinjection of any drug. ${ }^{*} p<0.05,{ }^{*} p<0.01$ compared with the effect of agonist alone.
CFA-treated rats at 2 weeks (38.9 ng) was significantly less than that in saline-treated rats $(89.0 \mathrm{ng} ; p<0.01)$.

Pretreatment with $8 \mathrm{ng}$ NTB did not shift the dose-response relationship of DAMGO for the contralateral hindpaw of rats injected $4 \mathrm{hr}$ earlier with CFA (Fig. 3C, Table 1). It did not antagonize either the marginal enhancement of the potency of DAMGO or its antinociceptive effects (Fig. $4 A$ ). In contrast, in rats that had received an intraplantar injection of CFA 2 weeks earlier, this same dose of NTB shifted the dose-response relationship of DAMGO to the right by 10 -fold in a competitive manner (Fig. 3D, Table 1). Figure $4 B$ further illustrates that this latter effect was restricted to an antagonism of the enhancement of the potency of DAMGO and did not extend to antagonism of its antinociceptive potency. Thus, the $\mathrm{ED}_{50}$ value for DAMGO in rats that were injected 2 weeks earlier with CFA, and in which NTB was microinjected in the RVM, did not differ from the $\mathrm{ED}_{50}$ value of DAMGO in saline-treated rats (Table 1).

The dose-effect relationship of DAMGO in rats treated 2 weeks earlier with CFA was characterized by a dog-leg wherein very low doses produced antinociception; this effect was not dose-dependent over a 100 -fold dose range (0.003-0.3 ng). It was noted that CTAP only marginally antagonized the antinociceptive effect of $1 \mathrm{ng}$ of DAMGO yet paradoxically produced a greater antagonism of $10 \mathrm{ng}$ of DAMGO (Fig. 3D). Microinjection of NTB also produced a partial antagonism of the antinociceptive effect of $1 \mathrm{ng}$ of DAMGO (Figs. 3D, 4B). However, when CTAP and NTB were coadministered, the antinociceptive effect of $1 \mathrm{ng}$ of DAMGO was completely antagonized $(9.2 \pm 0.8 \mathrm{sec})$. That neither dose alone completely antagonized the effects of DAMGO, yet the two did so when coadministered, suggests that $1 \mathrm{ng}$ of DAMGO interacts in an additive manner with an endogenous $\delta$ ORA. Finally, the increase in PWL produced by a lower dose of DAMGO, $0.03 \mathrm{ng}$, was completely antagonized by microinjection of either CTAP or NTB (Fig. 3D). That either antagonist alone was sufficient to completely antagonize the enhanced antinociceptive effect of this low dose of DAMGO is consistent with a possible synergistic activation of $\mu$ and $\delta$ opioid receptors, although additional studies would be required to verify this. 
Figure 3. Dose-response relationships for DAMGO alone (ם) and in combination with either $0.33 \mu \mathrm{g}$ of CTAP $(\square)$ or $8 \mathrm{ng}$ of NTB $(\bigcirc)$ in rats that received an intraplantar injection of CFA either $4 \mathrm{hr}(A, C)$ or 2 weeks $(B, D)$ earlier. $A, B$, Effects of the antagonists on the antihyperalgesic effect of DAMGO as determined by the ipsilateral inflamed hindpaw. $C, D$, Effects of the antagonists on the antinociceptive effect of DAMGO as determined by the contralateral, uninflamed hindpaw. The horizontal dashed and solid lines represent the average baseline PWL of rats before and after the intraplantar injection of CFA, respectively. Solid lines represent the least squares linear regression of individual values 15 min after microinjection of DAMGO, the time of peak effect. Each symbol is the mean \pm SEM of determinations in 6-11 rats. Data for DAMGO alone are taken from Hurley and Hammond (2000).
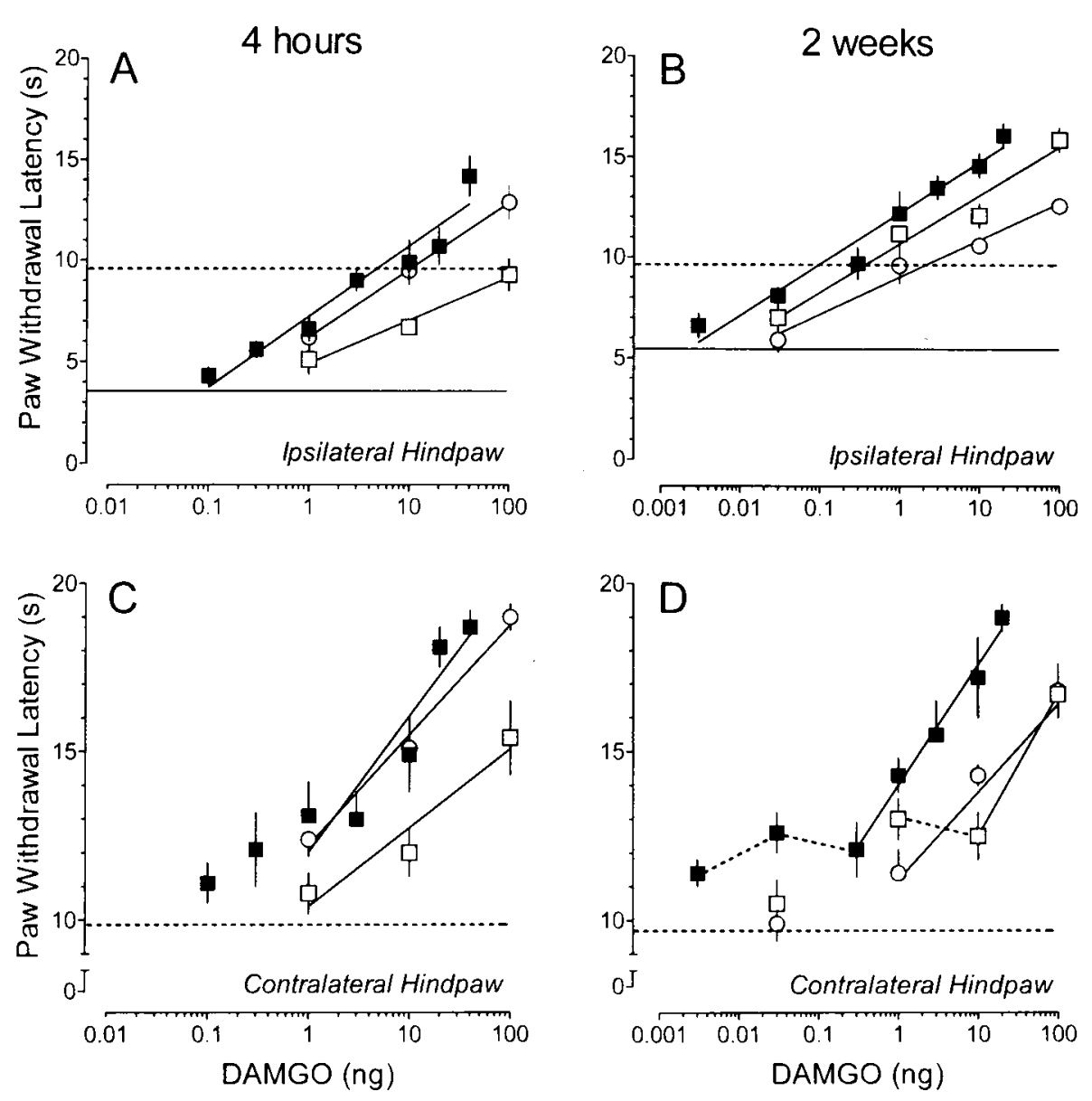

\section{RVM neurons in saline-treated rats are not subject to} a tonic, opioid-mediated input

Microinjection of $0.33 \mu \mathrm{g}$ of CTAP in the RVM of rats that had received an intraplantar injection of saline $4 \mathrm{hr}$ or 2 weeks earlier did not alter PWL of either the ipsilateral or contralateral hind-
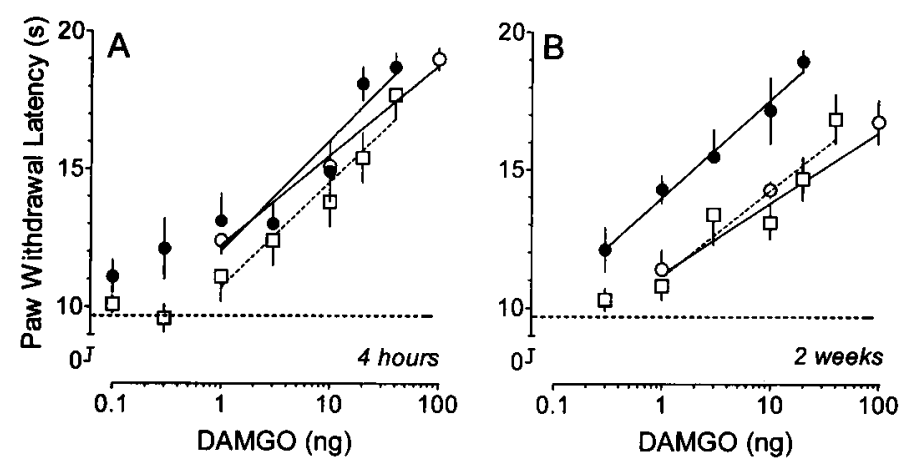

Figure 4. Dose-response relationships for DAMGO microinjected alone $(\mathbf{O}$, solid lines) or in combination with $8 \mathrm{ng}$ of NTB $(\bigcirc$, solid lines $)$ in the RVM of rats that received an intraplantar injection of CFA in one hindpaw either $4 \mathrm{hr}(A)$ or 2 weeks $(B)$ earlier, and the dose-response relationship of DAMGO in rats that received an intraplantar injection of saline ( $\square$, dashed lines) at the corresponding time. The values are the PWLs of the contralateral, uninjected hindpaw. Solid and dashed lines represent the least squares linear regression of the individual data at 15 min, the time of peak effect. Each symbol represents the mean \pm SEM of determinations in 6-11 rats. The horizontal dashed lines represent the average baseline PWL of rats after the intraplantar injection of CFA or saline, and before microinjection of the drugs. paw as compared with the effects of saline in the RVM (Fig. $5 A, B)$. This dose of CTAP did not produce any adverse motor effects. However, a 10-fold higher dose of CTAP produced severe motor impairment and abnormal behavior, including circling, hyperventilation, and abnormal postures in five of five rats. Microinjection of $80 \mathrm{ng}$ of NTB in the RVM of saline-treated rats also did not alter the PWL of either hindpaw as compared with the effects of saline (Fig. $5 A, B$ ). This dose of NTB did not produce any adverse behavioral effects.

\section{RVM neurons in CFA-treated rats receive a tonic, opioid input mediated by $\delta_{2}$ opioid receptors}

Microinjection of $0.33 \mu \mathrm{g}$ of CTAP in the RVM of rats that had received an intraplantar injection of CFA $4 \mathrm{hr}$ or 2 weeks earlier did not alter PWL of either the ipsilateral or contralateral hindpaw (Fig. $5 C-F$ ). In contrast, microinjection of $80 \mathrm{ng}$ of NTB in five CFA-treated rats produced behaviors indicative of nociception, including flinching of the inflamed hindpaw, excessive grooming, and freezing behavior. Mechanical allodynia was also present bilaterally on the hindpaws, flank, and abdomen. Neither ipsilateral nor contralateral PWL could be reliably measured in three of these rats because they simply would not place the inflamed hindpaw on the glass surface. This state was maintained for at least $60 \mathrm{~min}$. Microinjection of $8 \mathrm{ng}$ of NTB in the RVM of CFA-treated rats did not produce this constellation of behaviors. However, this dose of NTB decreased the withdrawal latency of the ipsilateral hindpaw in both the $4 \mathrm{hr}$ (Fig. 5C) and 2 week (Fig. $5 D$ ) treatment groups compared with the effect of saline in the RVM. Thus, NTB enhanced the CFA-induced hyperalgesia in 



Figure 5. Time course of PWL after microinjection of either saline (O), $0.33 \mu \mathrm{g}$ of CTAP $(\mathbf{\square}), 80 \mathrm{ng}$ of NTB $(\bullet)$, or 8 ng of NTB $(\mathbf{\Delta})$ in the RVM of saline $(A, B)$ - or CFA-treated $C-F)$ rats. Only the withdrawal latency of the ipsilateral hindpaw is depicted for rats that received an intraplantar injection of saline $4 \mathrm{hr}$ or 2 weeks earlier. The $80 \mathrm{ng}$ dose of NTB could not be tested in CFA-treated rats because it caused allodynia and hyperesthesia. BL1 represents the baseline PWL determined before intraplantar injection of saline or CFA. BL2 represents the baseline PWL after the intraplantar injection of saline or CFA, and before the microinjection of the antagonists. Each symbol represents the mean \pm SEM of determinations in six to eight rats, with the exception of CTAP in saline-treated rats at 2 weeks where $n=3$. ${ }^{*} p<0.05,{ }^{* *} p<0.01$ compared with saline at the corresponding time point.

these animals. This dose of NTB also significantly decreased the withdrawal latency of the contralateral hindpaw of CFA-treated rats. This effect was best observed in the 2 week treatment group (Fig. $5 F$ ); the decrease in the 4 hr treatment group did not achieve statistical significance (Fig. $5 E$ ). Thus, microinjection of NTB in the RVM effectively induced hyperalgesia in the uninjured, contralateral hindpaw of CFA-treated rats.

The hyperalgesia induced by NTB was not secondary to an increase in either paw diameter or paw temperature. Microinjection of $8 \mathrm{ng}$ of $\mathrm{NTB}$ in the RVM of rats that received an intraplantar injection of CFA $4 \mathrm{hr}$ earlier did not alter either the temperature or the diameter of the ipsilateral $\left(33.7 \pm 0.3^{\circ} \mathrm{C} ; 9.5 \pm\right.$ $0.3 \mathrm{~mm})$ or contralateral $\left(28.6 \pm 0.4^{\circ} \mathrm{C} ; 6.0 \pm 0.4 \mathrm{~mm}\right)$ hindpaws compared with the effect of saline (ipsilateral: $34.0 \pm 0.2^{\circ} \mathrm{C} ; 9.5 \pm$ $0.2 \mathrm{~mm}$; contralateral: $29.6 \pm 0.6^{\circ} \mathrm{C}, 6.1 \pm 0.1 \mathrm{~mm} ; p>0.3$, both paws). The effects of CTAP on paw temperature or diameter were not assessed because it did not affect PWL.

\section{Persistent inflammatory nociception is associated with an increase in the levels of endogenous enkephalins in brainstem nuclei}

Figure 6 illustrates tissue levels of $\left[\mathrm{Met}^{5}\right]$ enkephalin in nine different regions of the brainstem of saline- and CFA-treated rats. The location and relative size of the tissue punches are also illustrated in this Figure. Intraplantar injection of CFA was associated with a time-dependent increase in the levels of $\left[\mathrm{Met}^{5}\right]$ enkephalin in some but not all nuclei. Levels of [ $\mathrm{Met}^{5}$ ]enkephalin in the NRM were increased $4 \mathrm{~d}$ and 2 weeks but not $4 \mathrm{hr}$ after the injection of CFA as compared with levels in saline-treated rats.
Levels of $\left[\mathrm{Met}^{5}\right]$ enkephalin were similarly increased by three- to fourfold within the adjacent $\mathrm{NGCp} \alpha$ both ipsilateral and contralateral to the injury $4 \mathrm{hr}$ and $4 \mathrm{~d}$ after injection of CFA. Levels of $\left[\mathrm{Met}^{5}\right]$ enkephalin were also increased at 2 weeks in the contralateral $\mathrm{NGCp} \alpha$, but the increase in the ipsilateral $\mathrm{NGCp} \alpha$ failed to achieve statistical significance $(p=0.1)$. In the caudal aspect of the ventrolateral PAG, the levels of $\left[\mathrm{Met}^{5}\right]$ enkephalin were uniformly increased by 2.5-fold regardless of time after injury. A similar but smaller increase occurred in the rostral aspect of the ventrolateral PAG. Levels of $\left[\mathrm{Met}^{5}\right]$ enkephalin were also increased in both the ipsilateral and contralateral parabrachial region as a consequence of injury. However, the largest increase occurred in the parabrachial contralateral to the injury. Levels of $\left[\mathrm{Met}^{5}\right]$ enkephalin in this region increased progressively as a function of time after the injection of CFA, with a nearly 10 -fold increase evident by 2 weeks. Within the microcellular tegmental nucleus, levels of [ $\mathrm{Met}^{5}$ ]enkephalin were increased $4 \mathrm{~d}$ and 2 weeks after the injection of CFA both ipsilateral and contralateral to the injury, as well as by $4 \mathrm{hr}$ on the side ipsilateral to the injury.

Basal tissue levels of $\left[\mathrm{Leu}^{5}\right]$ enkephalin in saline-treated rats ranged from one-half to one-third those of $\left[\mathrm{Met}^{5}\right]$ enkephalin in the corresponding nucleus. Intraplantar injection of CFA was also associated with an increase in the tissue levels of [ $\left.\mathrm{Leu}^{5}\right]$ enkephalin, although the increase rarely exceeded twofold and was more restricted in its distribution. For example, levels of [ $\left.\mathrm{Leu}^{5}\right]$ enkephalin were significantly increased in the NRM of rats 2 weeks after the injection of CFA $(1.02 \pm 0.2 \mathrm{pmol} / \mathrm{mg}$ protein $)$ as compared with 
Figure 6. Levels of $\left[\mathrm{Met}^{5}\right]$ enkephalin (picomole per milligram of protein) in brainstem nuclei of rats that received an intraplantar injection of saline or of CFA either $4 \mathrm{hr}, 4 \mathrm{~d}$, or 2 weeks earlier. The location and relative size of each punch is depicted on the adjacent sections from the atlas of Paxinos and Watson (1997). For the NRM, caudal PAG, and rostral PAG, two punches were combined. NRM, Nucleus raphe magnus; $N G C p \alpha$, nucleus reticularis gigantocellularis pars $\alpha$; $P A G$, periaqueductal gray; $M i T g$, microcellular tegmental nucleus; $P B$, parabrachial nucleus. Each bar represents the mean \pm SEM of determinations in $6-11$ rats. Note the ordinate for the contralateral parabrachial nucleus differs from those in the other panels by a factor of 2.5 . ${ }^{*} p<0.05, * * p<0.01$ compared with values in saline-treated rats for that region.


saline-treated rats $(0.49 \pm 0.04 \mathrm{pmol} / \mathrm{mg}$ protein; $p<0.01)$. Tissue levels of $\left[\mathrm{Leu}^{5}\right]$ enkephalin were uniformly increased in the caudal ventrolateral PAG $4 \mathrm{hr}(1.15 \pm 0.25 \mathrm{pmol} / \mathrm{mg}$ protein $), 4 \mathrm{~d}$ $(1.16 \pm 0.18 \mathrm{pmol} / \mathrm{mg}$ protein), and 2 weeks $(1.18 \pm 0.17$ $\mathrm{pmol} / \mathrm{mg}$ protein) after the injection of CFA as compared with saline-treated rats $(0.55 \pm 0.03 \mathrm{pmol} / \mathrm{mg}$ protein; $p<0.05$, all times). A smaller increase in the levels of $\left[\mathrm{Leu}^{5}\right]$ enkephalin occurred in the rostral aspect of the ventrolateral PAG at all time points. Finally, levels of [ $\left.\mathrm{Leu}^{5}\right]$ enkephalin were also increased in the contralateral microcellular tegmental nucleus $4 \mathrm{~d}$ after the injection of CFA $(0.53 \pm 0.04 \mathrm{pmol} / \mathrm{mg}$ protein $)$ compared with levels in saline-treated rats $(0.38 \pm 0.02 \mathrm{pmol} / \mathrm{mg}$ protein; $p<$ $0.05)$.

\section{DISCUSSION}

The present findings provide direct support for our proposal (Hurley and Hammond, 2000) that enhancement of the antinociceptive and antihyperalgesic effects of DAMGO in CFA-treated rats is attributable to increased levels of endogenous opioid peptides within the RVM that have preferential affinity for the $\delta$ opioid receptor. They also provide provocative evidence that additional mechanisms may contribute to the upregulation of activity in pain modulatory pathways after the induction of persistent inflammatory nociception.

Neither CTAP nor NTB altered PWL when microinjected in the RVM of saline-treated rats, suggesting that RVM neurons do not normally receive tonically active opioid inputs (Kiefel et al., 1993; Roychowdhury and Fields, 1996; Thorat and Hammond, 1997; Hirakawa et al., 1999). Yet, in CFA-treated rats, microinjection of NTB in the RVM decreased PWL in both the ipsilat- eral and contralateral hindpaws. Because an antagonist exerts no effect in the absence of agonist, this finding suggested that inflammatory nociception evoked the release of opioid peptides in the RVM that act preferentially at $\delta$ opioid receptors. $\left[\mathrm{Met}^{5}\right]$ enkephalin and $\left[\mathrm{Leu}^{5}\right]$ enkephalin were considered likely candidates because they are 10-fold selective for the $\delta$ opioid receptor in vitro (Corbett et al., 1993) and act preferentially at this receptor when released in vivo (Takemori and Portoghese, 1993; Tseng et al., 1995). Indeed, levels of $\left[\mathrm{Met}^{5}\right]$ enkephalin and $\left[\mathrm{Leu}^{5}\right]$ enkephalin were increased in the RVM of CFA-treated rats. They were also increased in the parabrachial and microcellular tegmental nuclei, which contain enkephalinergic neurons that project to the RVM (Beitz, 1982; Williams and Klobuchar, 1998). These increases occurred most consistently $4 \mathrm{~d}$ and 2 weeks after the induction of inflammation, when the antinociceptive and antihyperalgesic effects of DAMGO were progressively enhanced. An increase in enkephalin release would disinhibit or activate OFF cells in the RVM (Harasawa et al., 2000) and be consistent with an activation of bulbospinal pain inhibitory pathways under conditions of inflammatory nociception (Ren and Dubner, 1996; Wei et al., 1999).

Although PWLs of the contralateral hindpaws of CFA-treated rats were not increased relative to those of saline-treated rats as initially expected (Hurley and Hammond, 2000; this study), $\delta$ ORAs are less efficacious than $\mu$ ORAs in producing antinociception after microinjection in the RVM (Rossi et al., 1994; Hurley and Hammond, 2000) or stimulating GTP $\gamma$ S binding in the medulla (Hurley et al., 2000). Thus, although the increase in enkephalin in the RVM was not sufficient to produce a frank 
antinociception, it was "unmasked" by NTB. The increase in enkephalin synthesis in the RVM therefore represents a compensatory response to mitigate the full expression of inflammatory nociception. Although such an increase was demonstrated in the spinal cord (Noguchi et al., 1992; Ossipov et al., 1996), this report is the first to demonstrate its occurrence supraspinally.

Substantial evidence indicates that $\delta$ ORAs can potentiate the antinociceptive effects of $\mu$ ORAs (Roerig and Fujimoto, 1989; Malmberg and Yaksh, 1992; Porreca et al., 1992; Adams et al., 1993; Ossipov et al., 1995; He and Lee, 1998). Naltriben blocked the enhancement of the antinociceptive effects of DAMGO but not its antinociceptive effects when microinjected at the same site in the RVM. This finding provides the first evidence that the RVM is an important site for the synergistic or additive interaction of $\delta$ and $\mu$ ORAs. The interaction may result from coincident activation of $\mu$ and $\delta$ opioid receptors colocalized to the same neurons (Wang and Wessendorf, 1999) or the activation of neurons of complementary function (Harasawa et al., 2000) within the RVM.

The increase in enkephalin in nuclei other than the RVM suggests that the mechanisms that subserve the enhancement of the effects of DAMGO are not necessarily restricted to the RVM. Additive or synergistic interactions can occur between $\mu$ and $\delta$ ORAs administered at disparate sites, such as DAMGO in the RVM and DELT in the PAG (Kiefel et al., 1993; Rossi et al., 1994). Enkephalin levels were also increased in the PAG of CFA-treated rats. The enhancement of the antinociceptive and antihyperalgesic potency of DAMGO in the RVM therefore may also be mediated by a synergistic or additive interaction of the exogenously administered $\mu$ ORA with enkephalins the release of which is increased in the PAG. The widespread increase in enkephalin suggests that similar mechanisms may exist for an enhancement of the endocrine, autonomic, or addictive effects of $\mu$ ORAs under conditions of inflammatory nociception.

The study design did not permit a definitive conclusion regarding whether the interaction that subserves the enhancement of the effects of DAMGO was synergistic or additive. The manner in which $\mu$ and $\delta$ ORAs interact is dependent on the dose ratio of the agonists (Adams et al., 1993; He and Lee, 1998). In this study, the amount of enkephalin released was probably constant, whereas increasing doses of DAMGO were microinjected to construct a dose-response relationship. This feature increased the likelihood that the nature of the interaction would differ along the continuum of doses, because the ratio of exogenous $\mu$ ORA to endogenous $\delta$ ORA was changing continually. Nonetheless, the ability of NTB to completely, rather than partially, antagonize the enhancement of DAMGO throughout the linear portion of its dose-response relationship 2 weeks after the injection of CFA suggested that the interaction was largely synergistic. Different conclusions were reached for the extremely low doses of DAMGO that comprised the dog-leg in the dose-response relationship. The enhancement of $1 \mathrm{ng}$ of DAMGO appeared to be additive, whereas that of $0.03 \mathrm{ng}$ appeared synergistic. Studies in which the agonists are administered in fixed dose ratios will be required to define the nature of the interaction.

These data do not exclude a contribution by other endogenous opioid peptides. $\beta$-Endorphin binds with equal potency to $\delta$ and $\mu$ opioid receptors (Corbett et al., 1993). However, $\beta$-endorphin does not appear to act preferentially at $\delta$ opioid receptors in vivo. When administered intracerebroventricularly, its antinociceptive effects are not antagonized by intracerebroventricular administration of $\delta$ opioid receptor antagonists or antisense oligode- oxynucleotides (Heyman et al., 1989; Wang et al., 1996; but see Shook et al., 1988). Also, molar quantities of $\beta$-endorphin in the RVM are 1/10 those of [Met ${ }^{5}$ ]enkephalin (Rossier et al., 1977; Palkovits and Eskay, 1987; this study), and $\beta$-endorphinimmunoreactive fibers are sparse (Bloom et al., 1978; Finley et al., 1981). The greater density of $\beta$-endorphin-immunoreactive fibers in the PAG and parabrachial nuclei (Finley et al., 1981; Palkovits and Eskay, 1987), however, suggests that further investigation may be warranted.

The increase in apparent affinity of NTB in CFA-treated rats was most intriguing. The affinity of a competitive antagonist is characteristic of the receptor at which it binds (Kenakin, 1997). The dose of NTB that induced hyperalgesia and antagonized the enhanced effects of DAMGO in CFA-treated rats was 10-fold less than the dose that antagonized DELT in the saline-treated rat. It also antagonized DELT in CFA but not saline-treated rats (our unpublished observations). This decrease in dose suggested that $\delta$ opioid receptors in CFA-treated rats bound NTB with higher affinity. The potency of CTAP also differed. Four hours after the induction of inflammation, CTAP antagonized the effects of DAMGO to the predicted extent. Yet 2 weeks after the injection of CFA, CTAP was less effective than predicted, suggesting that $\mu$ opioid receptors in CFA-treated rats bound CTAP with lower affinity. The basis for these divergent changes in receptor affinity is unclear. However, the change in apparent affinity is provocative evidence that persistent inflammatory nociception may alter the properties of $\mu$ and $\delta$ opioid receptors in the RVM. In vitro evidence indicates that $\delta$ opioid receptors can heterodimerize with $\delta$ opioid receptors (George et al., 2000; Gomes et al., 2000), supporting an earlier proposal that these receptors can associate as a functional complex (Vaught and Takemori, 1979; Rothman and Westfall, 1982; Schoffelmeer et al., 1990). The $\mu-\delta$ dimer exhibited 10-fold lower affinity for prototypic $\mu$ and $\delta$ OR As, yet a two- to three-fold higher affinity for $\left[\mathrm{Leu}^{5}\right]$ enkephalin (George et al., 2000). Extremely low doses of $\delta$ opioid receptor agonist or antagonist greatly increased the binding of DAMGO, as well as its potency and efficacy in stimulating phosphorylation of MAP kinase (Gomes et al., 2000). The affinity of antagonists for the $\mu-\delta$ dimer has not been determined. However, one could speculate that inflammation leads to changes in the proportion of $\mu$ and $\delta$ opioid receptors that associate as a functional complex in the RVM, which is evident here as a change in the apparent affinity of the antagonists.

To conclude, persistent inflammatory nociception increases the synthesis and presumably the release of enkephalins in many brainstem nuclei implicated in pain modulation. This increase represents a compensatory response by the CNS to mitigate the full magnitude of nociception but also serves to enhance the effects of exogenously administered $\mu$ ORAs through either an additive or synergistic interaction. Inflammatory nociception may also lead to changes in the association of $\mu$ and $\delta$ opioid receptors, resulting in a complex that not only binds endogenously released enkephalins with greater affinity, but in so doing enhances the actions of exogenously administered $\mu$ opioid receptor agonists. This latter possibility remains to be confirmed.

\section{REFERENCES}

Adams JU, Tallarida RJ, Geller EB, Adler MW (1993) Isobolographic superadditivity between delta and mu opioid agonists in the rat depends on the ratio of compounds, the mu agonist and the analgesic assay used. J Pharmacol Exp Ther 266:1261-1267.

Beitz AJ (1982) The organization of afferent projections to the midbrain periaqueductal gray of the rat. Neuroscience 7:133-159. 
Berge OG, Garcia-Cabrera I, Hole K (1988) Response latencies in the tail-flick test depend on tail skin temperature. Neurosci Lett 86:284-288.

Bloom F, Battenberg E, Rossier J, Ling N, Guillemin R (1978) Neurons containing $\beta$-endorphin in rat brain exist separately from those containing enkephalin: immunocytochemical studies. Proc Natl Acad Sci USA 75:1591-1595.

Corbett AD, Paterson SJ, Kosterlitz HW (1993) Selectivity of ligands for opioid receptors. In: Handbook of experimental pharmacology (Herz A, ed), pp 645-679. Berlin: Springer.

Dirig DM, Salami A, Rathbun ML, Ozaki GT, Yaksh TL (1997) Characterization of variables defining hindpaw withdrawal latency evoked by radiant thermal stimuli. J Neurosci Methods 76:183-191.

Donaldson LF, Harmar AJ, McQueen DS, Seckl JR (1992) Increased expression of preprotachykinin, calcitonin gene-related peptide, but not vasoactive intestinal peptide messenger RNA in dorsal root ganglia during the development of adjuvant monoarthritis in the rat. Mol Brain Res 16:143-149.

Finley JCW, Lindstrom P, Petrusz P (1981) Immunocytochemical localization of $\beta$-endorphin-containing neurons in the rat brain. Neuroendocrinology 33:28-42.

Finney DJ (1964) Statistical method in biological assay. New York: Hafner.

George SR, Fan T, Xie Z, Tse R, Tam V, Varghese G, O'Dowd BF (2000) Oligomerization of $\mu$ - and $\delta$-opioid receptors. J Biol Chem 275:26128-26135

Goff JR, Burkey AR, Goff DJ, Jasmin L (1998) Reorganization of the spinal dorsal horn in models of chronic pain: correlation with behavior. Neuroscience 82:559-574.

Gomes I, Jordan BA, Gupta A, Trapaidze N, Nagy V, Devi LA (2000) Heterodimerization of $\mu$ and $\delta$ opioid receptors: A role in opiate synergy. J Neurosci 20:RC110 (1-5).

Harasawa I, Fields HL, Meng ID (2000) Delta opioid receptor mediated actions in the rostral ventromedial medulla on tail flick latency and nociceptive modulatory neurons. Pain 85:255-262.

Hargreaves K, Dubner R, Brown F, Flores C, Joris J (1988) A new and sensitive method for measuring thermal nociception in cutaneous hyperalgesia. Pain 32:77-88.

He L, Lee NM (1998) Delta opioid receptor enhancement of mu opioid receptor-induced antinociception in spinal cord. J Pharmacol Exp Ther 285:1181-1186.

Herrero JF, Cervero F (1996) Supraspinal influences on the facilitation of rat nociceptive reflexes induced by carrageenan monoarthritis. Neurosci Lett 209:21-24.

Heyman JS, Vaught JL, Mosberg HI, Haaseth RC, Porreca F (1989) Modulation of $\mu$-mediated antinociception by $\delta$ agonists in the mouse: selective potentiation of morphine and normorphine by [D-Pen ${ }^{2}$, D-Pen ${ }^{5}$ ]enkephalin. Eur J Pharmacol 165:1-10.

Hirakawa N, Tershner SA, Fields HL (1999) Highly delta selective antagonists in the RVM attenuate the antinociceptive effect of PAG DAMGO. NeuroReport 10:3125-3129.

Hurley RW, Hammond DL (2000) The analgesic effects of supraspinal $\mu$ and $\delta$ opioid receptor agonists are potentiated during persistent inflammation. J Neurosci 20:1249-1259.

Hurley RW, Grabow TS, Tallarida RJ, Hammond DL (1999) Interaction between medullary and spinal $\delta_{1}$ and $\delta_{2}$ opioid receptors in the production of antinociception in the rat. J Pharmacol Exp Ther 289:993-999.

Hurley RW, Mizoguchi H, Tseng LF, Hammond DL (2000) Effects of $\mu$ and $\delta$ opioid receptor ligands on G-protein activation in the rostral ventromedial medulla of rats with persistent inflammation. Abstr Soc Neurosci 26:1066.

Hylden JLK, Nahin RL, Traub RJ, Dubner R (1989) Expansion of receptive fields of spinal lamina I projection neurons in rats with unilateral adjuvant-induced inflammation: the contribution of dorsal horn mechanisms. Pain 37:229-243.

Ji R-R, Zhang Q, Law P-Y, Low HH, Elde R, Hökfelt T (1995) Expression of $\mu-, \delta$, , and $\kappa$-opioid receptor-like immunoreactivities in rat dorsal root ganglia after carrageenan-induced inflammation. J Neurosci $15: 8156-8166$.

Kauppila T, Kontinen VK, Pertovaara A (1998) Influence of spinalization on spinal withdrawal reflex responses varies depending on the submodality of the test stimulus and the experimental pathological condition in the rat. Brain Res 797:234-242.

Kenakin TP (1997) Pharmacological analysis of drug-receptor interaction. New York: Raven.

Kiefel JM, Rossi GC, Bodnar RJ (1993) Medullar $\mu$ and $\delta$ opioid receptors modulate mesencephalic morphine analgesia in rats. Brain Res 624:151-161.

Leslie TA, Emson PC, Dowd PM, Woolf CJ (1995) Nerve growth factor contributes to the up-regulation of growth-associated protein 43 and preprotachykinin A messenger RNAs in primary sensory neurons following peripheral inflammation. Neuroscience 67:753-761.

MacArthur L, Ren K, Pfaffenroth E, Franklin E, Ruda MA (1999) Descending modulation of opioid-containing nociceptive neurons in rats with peripheral inflammation and hyperalgesia. Neuroscience 88:499-506.

Malmberg AB, Yaksh TL (1992) Isobolographic and dose-response analyses of the interaction between intrathecal mu and delta agonists: effects of naltrindole and its benzofuran analog (NTB). J Pharmacol Exp Ther 263:264-275.

McCarson KE, Krause JE (1994) NK-1 and NK-3 type tachykinin receptor mRNA expression in the rat spinal cord dorsal horn is increased during adjuvant or formalin-induced nociception. $\mathrm{J}$ Neurosci 14:712-720.

Neumann S, Doubell TP, Leslie T, Woolfe CJ (1996) Inflammatory pain hypersensitivity mediated by phenotypic switch in myelinated primary sensory neurons. Nature 384:360-364

Noguchi K, Ruda MA (1992) Gene regulation in an ascending nociceptive pathway: inflammation-induced increase in preprotachykinin mRNA in rat lamina I spinal projection neurons. J Neurosci 12:2563-2572.

Noguchi K, Morita Y, Kiyama H, Ono K, Tohyama M (1988) A noxious stimulus induces the preprotachykinin-A gene expression in the rat dorsal root ganglion: a quantitative study using in situ hybridization histochemistry. Mol Brain Res 4:31-35.

Noguchi K, Morita Y, Kiyama H, Sato M, Ono K, Tohyama M (1989) Preproenkephalin gene expression in the rat spinal cord after noxious stimuli. Mol Brain Res 5:227-234.

Noguchi K, Dubner R, Ruda MA (1992) Preproenkephalin mRNA in spinal dorsal horn neurons is induced by peripheral inflammation and is co-localized with fos and fos-related proteins. Neuroscience 46:561-570.

Ossipov MH, Kovelowski CJ, Porreca F (1995) The increase in morphine antinociceptive potency produced by carrageenan-induced hindpaw inflammation is blocked by naltrindole, a selective $\delta$-opioid antagonist. Neurosci Lett 184:173-176.

Ossipov MH, Kovelowski CJ, Wheeler-Aceto H, Cowan A, Hunter JC, Lai J, Malan TP, Porreca F (1996) Opioid antagonists and antisera to endogenous opioids increase the nociceptive response to formalin: demonstration of an opioid kappa and delta inhibitory tone. J Pharmacol Exp Ther 277:784-788.

Palkovits M, Eskay RL (1987) Distribution and possible origin of $\beta$-endorphin and $\mathrm{ACTH}$ in discrete brainstem nuclei of rats. Neuropeptides 9:123-137.

Paxinos G, Watson C (1997) The rat brain in stereotaxic coordinates, Ed 4. San Diego: Academic.

Porreca F, Jiang Q, Tallarida RJ (1990) Modulation of morphine antinociception by peripheral [ $\left.\mathrm{Leu}^{5}\right]$ enkephalin: a synergistic interaction. Eur J Pharmacol 179:463-468.

Porreca F, Takemori AE, Sultana M, Portoghese PS, Bowen WD, Mosberg HI (1992) Modulation of mu-mediated antinociception in the mouse involves opioid delta-2 receptors. J Pharmacol Exp Ther 263:147-152.

Ren K, Dubner R (1996) Enhanced descending modulation of nociception in rats with persistent hindpaw inflammation. J Neurophysiol 76:3025-3037.

Roerig SC, Fujimoto JM (1989) Multiplicative interaction between intrathecally and intracerebroventricularly administered mu opioid agonists but limited interactions between delta and kappa agonists for antinociception in mice. J Pharmacol Exp Ther 249:762-768.

Rossi GC, Pasternak GW, Bodnar RJ (1994) $\mu$ and $\delta$ opioid synergy between the periaqueductal gray and the rostro-ventral medulla. Brain Res 665:85-93.

Rossier J, Vargo TM, Minick S, Ling N, Bloom FE, Guillemin R (1977) Regional dissociation of $\beta$-endorphin and enkephalin contents in rat brain and pituitary. Proc Natl Acad Sci USA 74:5162-5165.

Rothman RB, Westfall TC (1982) Allosteric coupling between morphine and enkephalin receptors in vitro. Mol Pharmacol 21:548-557.

Roychowdhury SM, Fields HL (1996) Endogenous opioids acting at a medullary $\mu$-opioid receptor contribute to the behavioral antinociception produced by GABA antagonism in the midbrain periaqueductal gray. Neuroscience 74:863-872.

Schaible HG, Schmidt RF (1988) Time course of mechanosensitivity changes in articular afferents during a developing experimental arthritis. J Neurophysiol 60:2180-2195.

Schaible H-G, Neugebauer V, Cervero F, Schmidt RF (1991) Changes in tonic descending inhibition of spinal neurons with articular input during the development of acute arthritis in the cat. J Neurophysiol 66:1021-1032.

Schoffelmeer AN, Yao YH, Gioannini TL, Hiller JM, Ofri D, Roques BP, Simon EJ (1990) Cross-linking of human $\left[{ }^{125} \mathrm{I}\right] \beta$-endorphin to opioid receptors in rat striatal membranes: biochemical evidence for the existence of a mu/delta opioid receptor complex. J Pharmacol Exp Ther 253:419-426.

Shook JE, Kazmierski W, Wire WS, Lemcke PK, Hruby VJ, Burks TF (1988) Opioid receptor selectivity of $\beta$-endorphin in vitro and in vivo: mu, delta and epsilon receptors. J Pharmacol Exp Ther 246:1018-1025.

Smith PK, Krohn RI, Hermanson GT, Mallia AK, Gartner FH, Provenzano MD, Fujimoto EK, Goeke NM, Olson BJ, Klenk DC (1985) 
Measurement of protein using bicinchoninic acid. Anal Biochem 150:76-85.

Takemori AE, Portoghese PS (1993) Enkephalin antinociception in mice is mediated by $\delta_{1}$ - and $\delta_{2}$-opioid receptors in the brain and spinal cord, respectively. Eur J Pharmacol 242:145-150.

Tanaka M, Cummins TR, Ishikawa K, Dib-Hajj SD, Black JA, Waxman SG (1998) $\mathrm{SNS} \mathrm{Na}^{+}$channel expression increases in dorsal root ganglion neurons in the carrageenan inflammatory pain model. NeuroReport 9:967-972.

Terayama R, Guan Y, Dubner R, Ren K (2000) Activity-induced plasticity in brain stem pain modulatory circuitry after inflammation. NeuroReport 11:1915-1919.

Thomas DA, McGowan MK, Hammond DL (1995) Microinjection of baclofen in the ventromedial medulla of the rat produces antinociception or hyperalgesia. J Pharmacol Exp Ther 275:274-284.

Thorat SN, Hammond DL (1997) Modulation of nociception by microinjection of delta-1 and delta-2 opioid receptor ligands in the ventromedial medulla of the rat. J Pharmacol Exp Ther 283:1185-1192.

Tseng LF, Tsai JH, Collins KA, Portoghese PS (1995) Spinal $\delta_{2^{-}}$, but not $\delta_{1-}$, or $\kappa$-opioid receptors are involved in the tail-flick inhibition induced by $\beta$-endorphin from nucleus raphe obscurus in the pentobarbital-anesthetized rat. Eur J Pharmacol 77:251-256.

Tsuruoka M, Willis WD (1996) Descending modulation from the region of the locus coeruleus on nociceptive sensitivity in a rat model of inflammatory hyperalgesia. Brain Res 743:86-92.

Urban MO, Jiang MC, Gebhart GF (1996) Participation of central descending nociceptive facilitatory systems in secondary hyperalgesia produced by mustard oil. Brain Res 737:83-91.
Urban MO, Zahn PK, Gebhart GF (1999) Descending facilitatory influences from the rostral medial medulla mediate secondary, but not primary hyperalgesia in the rat. Neuroscience 90:349-352.

Vaught JL, Takemori AE (1979) Differential effects of leucine and methionine enkephalin on morphine-induced analgesia, acute tolerance and dependence. J Pharmacol Exp Ther 208:86-90.

Wang H, Wessendorf MW (1999) $\mu$ - and $\delta$-opioid receptor mRNAs are expressed in spinally projecting serotonergic and nonserotonergic neurons of the rostral ventromedial medulla. J Comp Neurol 404:183-196.

Wang HQ, Kampine JP, Tseng LF (1996) Antisense oligodeoxynucleotide to a $\delta$-opioid receptor messenger RNA selectively blocks the antinociception induced by intracerebroventricularly administered $\delta$-, but not $\mu-, \epsilon$ - or $\kappa$-opioid receptor agonists in the mouse. Neuroscience 75:445-452.

Wei F, Ren K, Dubner R (1998) Inflammation-induced Fos protein expression in the rat spinal cord is enhanced following dorsolateral or ventrolateral funiculus lesions. Brain Res 782:136-141.

Wei F, Dubner R, Ren K (1999) Nucleus reticularis gigantocellularis and nucleus raphe magnus in the brain stem exert opposite effects on behavioral hyperalgesia and spinal Fos protein expression after peripheral inflammation. Pain 80:127-141.

Weihe E, Millan MJ, Höllt V, Nohr D, Herz A (1989) Induction of the gene encoding pro-dynorphin by experimentally induced arthritis enhances staining for dynorphin in the spinal cord of rat. Neuroscience 31:77-95.

Williams FG, Klobuchar RA (1998) Efferent projections of the rat microcellular tegmental nucleus: potential descending modulation in chronic nociception. Soc Neurosci Abstr 24:1133. 